\title{
Research on the Algorithm for Composite Lining of Deep Buried Water Conveyance Tunnel
}

\author{
Fei Li $\mathbb{D}^{1},{ }^{1}$ Ningdong Chang $\mathbb{D D}^{1}{ }^{1}$ Jianhui Wang $\mathbb{D},{ }^{2}$ Tao Feng $\mathbb{D}^{3},{ }^{3}$ and Chunling Li $^{4}{ }^{4}$ \\ ${ }^{1}$ School of Civil and Resource Engineering, University of Science and Technology Beijing, Beijing 100083, China \\ ${ }^{2}$ Beijing Institute of Water Science and Technology, Beijing 100048, China \\ ${ }^{3}$ Beijing South-to-North Water Diversion East Canal Management Office, Beijing 100176, China \\ ${ }^{4}$ School of Water Conservancy and Hydropower, Hohai University, Nanjing 210015, China \\ Correspondence should be addressed to Fei Li; lifei2016@ustb.edu.cn
}

Received 22 December 2020; Revised 1 January 2021; Accepted 19 January 2021; Published 2 February 2021

Academic Editor: Zhijie Wen

Copyright $\odot 2021 \mathrm{Fei} \mathrm{Li}$ et al. This is an open access article distributed under the Creative Commons Attribution License, which permits unrestricted use, distribution, and reproduction in any medium, provided the original work is properly cited.

Composite lining of deep buried water conveyance tunnel for bearing high internal water pressure is a new type of applicable structure. However, up to date, no effective method is available to calculate the stress of the structure. In this paper, a simplified algorithm, which can be used to calculate the stress distribution of composite lining accurately but costs little computational resource, is proposed. This algorithm, which is based on the elastic theory, takes the effect of internal water pressure and surrounding rock on the composite lining into consideration, respectively. Then, the stress distribution of composite lining in infinite body is derived on the basis of Lame solution. Finally, a case study is followed by choosing a typical section of the Eastern Canal in Beijing of the South-to-North Water Diversion Project (SNWDP). This case study was analysed by using the simplified algorithm and verified by finite element method with ABAQUS. The results show that the stress distribution of composite lining can be obtained quickly and accurately with the simplified algorithm, which can provide a reference for other engineering designs.

\section{Introduction}

At present, many large water conveyance tunnels have been built with composite lining method at home and abroad, such as SNWDP in China $[1,2]$. In the water conveyance tunnel, the secondary lining is considered to be a main loadbearing component. However, research studies on the composite lining under water pressure are relatively rare, especially when the composite lining bears both the high internal water pressure and in situ stress of the surrounding rock. In addition, there is no reasonable and unified calculation method for composite lining design. Therefore, it becomes a major theoretical research topic on how to devise an effective calculation method of composite lining under high internal pressure.

According to different mechanical models, the design methods of lining structures can be classified into three kinds, i.e., (modified) conventional method, multihinge ring method, and beam-spring model calculation method. The conventional method, which was put forward by Japanese standard in 1960 [3, 4], ignored the influence between the joints and assumed that the lining was a homogeneous ring. The modified conventional method [4-6] considered the influence of the joints on the basis of the conventional method and adopted the parameters $\eta$ and $\zeta$ to calculate the internal forces of the structure, considering the tube segment as a homogeneous ring with a stiffness of $\eta \mathrm{EI}$ and the design bending moment as $(1+\zeta) M$. The parameters $\eta$ and $\zeta$ were obtained mainly according to test or engineering experience, with $\eta$ being about $0.6-0.8$ and $\zeta$ being about $0.3-0.5$ [7]. Xiao et al. [8] improved the modified conventional method and proposed the load calculation model of lining located in soft and hard soil or soft soil and hard rock composite rock layer. The joints of the pipe pieces were considered as hinge structures in the multihinge ring method, which was suitable for the condition of high surrounding rock strength $[9,10]$. In the calculation method of the beam-spring model, the pipe slices were assumed to be beams, and the joints between 
the pipe slices were considered to be different springs [11], which were close to engineering practice. It can simulate the staggered joint problem well and has been widely used in various engineering designs currently. With the nonlinear characteristics of pipe joint considered, Shen et al. [12] established a beam-nonlinear spring model based on the beam-spring theory.

So far, no due attention has been given to the research of composite lining structure both at home and abroad. At present, the main research methods are experimental and finite element methods, and analytical methods are relatively few. The parameters of lining design obtained from different design theories may vary greatly due to different assumptions [13]. Moreover, most of the existing calculation methods for the composite lining of water conveyance tunnel are so conservative that the related design steps are complicated, resulting in high project cost. These methods are performed by following the guidelines issued by the International Tunnel Association [14]. In the International Tunnelling Association Guidelines, the structures of composite lining are only divided into double shell structures and composite structures; however, no specific model and analytical solution were given. Compared with the finite element method, the stress distribution under varied working conditions can be efficiently calculated by using the analytical method. El Naggar et al. [15] proposed an analytical method for composite lining, which took the interaction between the parts into consideration. However, the method is only applicable to the case that the bolt is symmetric on both the horizontal and vertical axes. Xu [16] proposed an analytical method of composite lining; however, this model is based on the single-layer sleeve mechanical model.

To sum up, the research on composite lining is still in its infancy and there is a lack of practical analytical method. In order to simplify this calculation and reduce the project cost, a simplified composite lining algorithm is put forward in this paper. Based on the engineering of the South-to-North Water Transfer Tunnel, a typical section was chosen. The analytical solution of the stress distribution of the composite lining was deduced and verified by the finite element method using ABAQUS, which could provide a reference for other engineering designs.

\section{A New Simplified Calculation Algorithm for Composite Lining}

In this paper, the deep buried water conveyance tunnel under high water pressure was taken as the research object. The calculation mainly considered the internal water pressure of the conveyance tunnel and the in situ stress field of surrounding rock to the lining. Based on the assumption of elasticity and deformation coordination, the analytical solution of stress for composite lining under high water pressure was given.

In general, a lining is mainly subjected to uniform internal and external water pressure. The mechanical model can be simplified as the axisymmetric stress problem of cylinder. For the in situ stress field of surrounding rock, its influence on the composite lining is mainly vertical and horizontal. The mechanical model can be simplified as the problem of stress concentration at the orifice.

2.1. Mechanical Model of Composite Lining considering Internal Water Pressure. For the internal pressure applied to the composite lining, the mechanical model is an axisymmetric stress problem. The internal water pressure is symmetric around the $Z$ axis. The stress component of the internal water pressure in the polar plane is only a function of $\rho$ and does not change with $\varphi$.

By using the semi-inverse method in elastic mechanics [17], the stress function is given by the following equation:

$$
\phi=\phi(\rho) .
$$

The stress formula is given by the following equation:

$$
\begin{gathered}
\sigma_{\rho}=\frac{1}{\rho} \frac{\mathrm{d} \phi}{\mathrm{d} \rho}, \\
\sigma_{\varphi}=\frac{\mathrm{d}^{2} \phi}{\mathrm{d} \rho^{2}}, \\
\tau_{\rho \varphi}=\tau_{\varphi \rho}=0 .
\end{gathered}
$$

The consistent equation can be expressed as follows:

$$
\left(\frac{\mathrm{d}^{2}}{\mathrm{~d} \rho^{2}}+\frac{1}{\rho} \frac{\mathrm{d}}{\mathrm{d} \rho}\right)\left(\frac{\mathrm{d}^{2} \phi}{\mathrm{d} \rho^{2}}+\frac{1}{\rho} \frac{\mathrm{d} \phi}{\mathrm{d} \rho}\right)=0 .
$$

By transforming Laplace operator $\nabla^{2}$ into another form, the consistent equation is obtained as shown in the following equation:

$$
\frac{1}{\rho} \frac{\mathrm{d}}{\mathrm{d} \rho}\left\{\rho \frac{\mathrm{d}}{\mathrm{d} \rho}\left[\frac{1}{\rho} \frac{\mathrm{d}}{\mathrm{d} \rho}\left(\rho \frac{\mathrm{d} \phi}{\mathrm{d} \rho}\right)\right]\right\}=0 .
$$

By solving this differential equation of the fourth order, the general solution of the stress function under axisymmetric stress state can be obtained as follows:

$$
\phi=A \ln \rho+B \rho^{2} \ln \rho+C \rho^{2}+D .
$$

Therefore, the general solution of axisymmetric stress is shown in the following equation:

$$
\begin{aligned}
& \sigma_{\rho}=\frac{A}{\rho^{2}}+B(1+2 \ln \rho)+2 C, \\
& \sigma_{\varphi}=-\frac{A}{\rho^{2}}+B(3+2 \ln \rho)+2 C, \\
& \tau_{\rho \varphi}=\tau_{\varphi \rho}=0,
\end{aligned}
$$

where $\sigma_{\rho}$ is the radial stress, $\sigma_{\varphi}$ is the circumferential stress, $\tau_{\rho \varphi}$ and $\tau_{\varphi \rho}$ are shear stresses, $\rho$ is the radius coordinate, and $A, B$, and $C$ are undetermined coefficients.

The conveyance tunnel bearing the internal water stress is a plane stress problem. By combining the stress components with the physical and geometric equations, the 
displacement components under the axisymmetric stress state can be obtained as follows:

$$
\begin{aligned}
u_{\rho}= & \frac{1}{E}\left[-(1+\mu) \frac{A}{\rho}+2(1-\mu) B \rho(\ln \rho-1)\right. \\
& +(1-3 \mu) B \rho+2(1-\mu) C \rho]+I \cos \varphi+K \sin \varphi, \\
u_{\varphi}= & \frac{4 B \rho \varphi}{E}+H \rho-I \sin \varphi+K \cos \varphi,
\end{aligned}
$$

where $u_{\rho}$ is the radial displacement, $u_{\varphi}$ is the circumferential displacement, $E$ is the elastic modulus, $\mu$ is Poisson's ratio, and $H, I$, and $K$ are undetermined coefficients.

For the composite lining model, it can be considered that the double cylinder is embedded in an infinite elastomer, as shown in Figure 1.

Inner boundary conditions of the inner lining are as follows:

$$
\left(\sigma_{\rho}\right)_{\rho=R_{1}}=-q .
$$

When there is no gap between the inner lining and the outer lining, it can be considered that the pipe is stressed together with the concrete lining [18]. In the combined stress model, the inner and outer lining deformation is coordinated. At the common boundary of inner lining and outer lining, the boundary conditions are given by the following equation:

$$
\begin{aligned}
& \left(\sigma_{\rho}\right)_{\rho=R_{2}}=\left(\sigma_{\rho}^{\prime}\right)_{\rho=R_{2}}, \\
& \left(u_{\rho}\right)_{\rho=R_{2}}=\left(u_{\rho}^{\prime}\right)_{\rho=R_{2}} .
\end{aligned}
$$

The boundary conditions on the contact surfaces of outer lining and infinite elastomer are given by the following equation:

$$
\left(\sigma_{\rho}^{\prime \prime}\right)_{\rho=R_{3}}=\left(\sigma_{\rho}^{\prime \prime}\right)_{\rho=R_{3}} .
$$

According to Saint-Venant's principle, the rock far away from the tunnel is not affected by the internal water pressure. So, at infinity of an elastomer, the boundary conditions are given by the following equation:

$$
\begin{aligned}
& \left(\sigma_{\rho}^{\prime \prime}\right)_{\rho \rightarrow \infty}=0, \\
& \left(\sigma_{\varphi}^{\prime \prime}\right)_{\rho \longrightarrow \infty}=0,
\end{aligned}
$$

where $\sigma_{\rho}$ and $\sigma_{\varphi}$ are the stresses on inner lining, $\sigma_{\rho}^{\prime}$ and $\sigma_{\varphi}^{\prime}$ are the stresses on outer lining, $\sigma_{\rho}^{\prime \prime}$ and $\sigma_{\varphi}^{\prime \prime}$ are the stresses on surrounding rock, $\mu_{\rho}$ is the radial displacement of inner lining, and $\mu_{\rho}^{\prime \prime}$ is the radial displacement of outer lining.

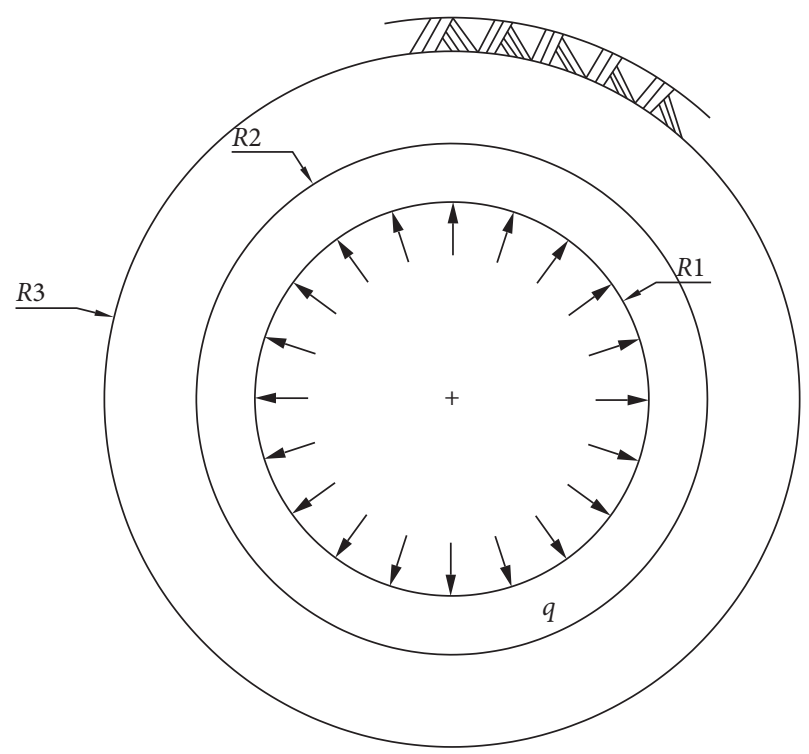

Figure 1: Double cylinder model embedded in an infinite elastomer.

On the contact surface between the outer lining and the surrounding rock, the outer lining and the infinite elastomer deform in harmony. Both have the same displacement. The displacement boundary condition is given by the following equation:

$$
\left(\mu_{\rho}^{\prime}\right)_{\rho=R_{3}}=\left(\mu_{\rho}^{\prime \prime}\right)_{\rho=R_{3}} \text {, }
$$

where $\mu_{\rho}^{\prime \prime}$ is the radial displacement of surrounding rock.

Combined with the above boundary conditions and single value displacement conditions, the analytic solution of stress distribution for inner lining can be obtained as follows:

$$
\begin{gathered}
\sigma_{\rho}=\frac{A_{1}}{\rho^{2}}+2 C_{1}, \\
\sigma_{\varphi}=-\frac{A_{1}}{\rho^{2}}+2 C_{1}, \\
\tau_{\rho \varphi}=\tau_{\varphi \rho}=0 .
\end{gathered}
$$

The analytical solution of the stress distribution for outer lining is as follows:

$$
\begin{gathered}
\sigma_{\rho}=\frac{A_{2}}{\rho^{2}}+2 C_{2}, \\
\sigma_{\varphi}=-\frac{A_{2}}{\rho^{2}}+2 C_{2}, \\
\tau_{\rho \varphi}=\tau_{\varphi \rho}=0,
\end{gathered}
$$

where the coefficients are given by equations (15) and (16). 


$$
\begin{aligned}
& A_{1}=\frac{a_{1}}{b_{1}}, \\
& C_{1}=\frac{m_{1}}{n_{1}}, \\
& A_{2}=\frac{a_{2}}{b_{1}}, \\
& C_{2}=\frac{m_{2}}{b_{1}},
\end{aligned}
$$

where $a_{1}, b_{1}, m_{1}, n_{1}, a_{2}$, and $m_{2}$ are given by the following equation:

$$
\begin{aligned}
& a_{1}=R_{1}^{2}\left(R _ { 2 } ^ { 2 } \left(\mu_{2}\left(E_{2}\left(E_{1}\left(R_{3}^{2} \mu_{3}+R_{3}^{2}\right)-E_{3} R_{3}^{2}\right)+E_{2} E_{3} R_{3}^{2} \mu_{1}\right)\right.\right. \\
& +E_{2}\left(E_{1}\left(R_{3}^{2} \mu_{3}+R_{3}^{2}\right)+E_{3} R_{3}^{2}\right)+\mu_{1}\left(E_{2}^{2}\left(-R_{3}^{2} \mu_{3}-R_{3}^{2}\right)-E_{2} E_{3} R_{3}^{2}\right) \\
& \left.+E_{2}^{2}\left(R_{3}^{2} \mu_{3}+R_{3}^{2}\right)-E_{1} E_{3} R_{3}^{2} \mu_{2}^{2}+E_{1} E_{3} R_{3}^{2}\right)+R_{2}^{4}\left(\mu_{1}\left(E_{2}^{2}\left(\mu_{3}+1\right)-E_{2} E_{3}\right)\right. \\
& \left.\left.+E_{2}\left(E_{1}\left(\mu_{3}+1\right)+E_{3}\right)+E_{2}^{2}\left(-\mu_{3}-1\right)+\mu_{2}\left(E_{2}\left(E_{1}\left(-\mu_{3}-1\right)+E_{3}\right)-E_{2} E_{3} \mu_{1}\right)+E_{1} E_{3} \mu_{2}^{2}-E_{1} E_{3}\right)\right) q \text {, } \\
& b_{1}=R_{1}^{2}\left(\mu_{2}\left(E_{2}\left(E_{1}\left(R_{3}^{2} \mu_{3}+R_{3}^{2}\right)+E_{3} R_{3}^{2}\right)+E_{2} E_{3} R_{3}^{2} \mu_{1}\right)+R_{2}^{2}\left(\mu_{1}\left(E_{2}^{2}\left(\mu_{3}+1\right)-E_{2} E_{3}\right)+\right.\right. \\
& \left.E_{2}\left(E_{1}\left(\mu_{3}+1\right)-E_{3}\right)+E_{2}^{2}\left(\mu_{3}+1\right)+\mu_{2}\left(E_{2}\left(E_{1}\left(-\mu_{3}-1\right)-E_{3}\right)-E_{2} E_{3} \mu_{1}\right)+E_{1} E_{3} \mu_{2}^{2}-E_{1} E_{3}\right) \\
& +E_{2}\left(E_{1}\left(R_{3}^{2} \mu_{3}+R_{3}^{2}\right)-E_{3} R_{3}^{2}\right)+\mu_{1}\left(E_{2}^{2}\left(-R_{3}^{2} \mu_{3}-R_{3}^{2}\right)-E_{2} E_{3} R_{3}^{2}\right)+E_{2}^{2}\left(-R_{3}^{2} \mu_{3}-R_{3}^{2}\right) \\
& \left.-E_{1} E_{3} R_{3}^{2} \mu_{2}^{2}+E_{1} E_{3} R_{3}^{2}\right)+R_{2}^{2}\left(\mu_{2}\left(E_{2}\left(E_{1}\left(-R_{3}^{2} \mu_{3}-R_{3}^{2}\right)+E_{3} R_{3}^{2}\right)-E_{2} E_{3} R_{3}^{2} \mu_{1}\right)+\right. \\
& \mu_{1}\left(E_{2}^{2}\left(R_{3}^{2} \mu_{3}+R_{3}^{2}\right)+E_{2} E_{3} R_{3}^{2}\right)+E_{2}\left(E_{1}\left(-R_{3}^{2} \mu_{3}-R_{3}^{2}\right)-E_{3} R_{3}^{2}\right)+E_{2}^{2}\left(-R_{3}^{2} \mu_{3}-R_{3}^{2}\right)+ \\
& \left.E_{1} E_{3} R_{3}^{2} \mu_{2}^{2}-E_{1} E_{3} R_{3}^{2}\right)+R_{2}^{4}\left(\mu_{2}\left(E_{2}\left(E_{1}\left(\mu_{3}+1\right)-E_{3}\right)+E_{2} E_{3} \mu_{1}\right)+E_{2}^{2}\left(\mu_{3}+1\right)\right. \\
& \left.+\mu_{1}\left(E_{2}^{2}\left(-\mu_{3}-1\right)+E_{2} E_{3}\right)+E_{2}\left(E_{1}\left(-\mu_{3}-1\right)-E_{3}\right)-E_{1} E_{3} \mu_{2}^{2}+E_{1} E_{3}\right), \\
& m_{1}=R_{1}^{2}\left(\mu_{2}\left(E_{2}\left(E_{1}\left(R_{3}^{2} \mu_{3}+R_{3}^{2}\right)+E_{3} R_{3}^{2}\right)+E_{2} E_{3} R_{3}^{2} \mu_{1}\right)+R_{2}^{2}\left(\mu_{1}\left(E_{2}^{2}\left(\mu_{3}+1\right)-E_{2} E_{3}\right)\right.\right. \\
& \left.\left.+E_{2}\left(E_{1}\left(\mu_{3}+1\right)-E_{3}\right)+E_{2}^{2}\left(\mu_{3}+1\right)+\mu_{2}\left(E_{2}\left(E_{1}\left(-\mu_{3}-1\right)-E_{3}\right)-E_{2} E_{3} \mu_{1}\right)+E_{1} E_{3} \mu_{2}^{2}-E_{1} E_{3}\right)\right) \\
& +E_{2}\left(E_{1}\left(R_{3}^{2} \mu_{3}+R_{3}^{2}\right)-E_{3} R_{3}^{2}\right)+\mu_{1}\left(E_{2}^{2}\left(-R_{3}^{2} \mu_{3}-R_{3}^{2}\right)-E_{2} E_{3} R_{3}^{2}\right) \\
& +E_{2}^{2}\left(-R_{3}^{2} \mu_{3}-R_{3}^{2}\right)-\left(E_{1} E_{3} R_{3}^{2} \mu_{2}^{2}+E_{1} E_{3} R_{3}^{2}\right) q \text {, } \\
& n_{1}=R_{1}^{2}\left(\mu_{2}\left(E_{2}\left(E_{1}\left(2 R_{3}^{2} \mu_{3}+2 R_{3}^{2}\right)+2 E_{3} R_{3}^{2}\right)+2 E_{2} E_{3} R_{3}^{2} \mu_{1}\right)+R_{2}^{2}\left(\mu_{1}\left(E_{2}^{2}\left(2 \mu_{3}+2\right)-2 E_{2} E_{3}\right)\right.\right. \\
& +E_{2}\left(E_{1}\left(2 \mu_{3}+2\right)-2 E_{3}\right)+E_{2}^{2}\left(2 \mu_{3}+2\right)+\mu_{2}\left(E_{2}\left(E_{1}\left(-2 \mu_{3}-2\right)-2 E_{3}\right)-2 E_{2} E_{3} \mu_{1}\right)+ \\
& \left.2 E_{1} E_{3} \mu_{2}^{2}-2 E_{1} E_{3}\right)+E_{2}\left(E_{1}\left(2 R_{3}^{2} \mu_{3}+2 R_{3}^{2}\right)-2 E_{3} R_{3}^{2}\right)+\mu_{1}\left(E_{2}^{2}\left(-2 R_{3}^{2} \mu_{3}-2 R_{3}^{2}\right)-2 E_{2} E_{3} R_{3}^{2}\right) \\
& \left.+E_{2}^{2}\left(-2 R_{3}^{2} \mu_{3}-2 R_{3}^{2}\right)-2 E_{1} E_{3} R_{3}^{2} \mu_{2}^{2}+2 E_{1} E_{3} R_{3}^{2}\right)+R_{2}^{2}\left(\mu_{2}\left(E_{2}\left(E_{1}\left(-2 R_{3}^{2} \mu_{3}-2 R_{3}^{2}\right)+2 E_{3} R_{3}^{2}\right)-2 E_{2} E_{3} R_{3}^{2} \mu_{1}\right)\right. \\
& +\mu_{1}\left(E_{2}^{2}\left(\left(2 R_{3}^{2} \mu_{3}+2 R_{3}^{2}\right)+2 E_{2} E_{3} R_{3}^{2}\right)+E_{2}\left(E_{1}\left(-2 R_{3}^{2} \mu_{3}-2 R_{3}^{2}\right)-2 E_{3} R_{3}^{2}\right)+\right. \\
& \left.E_{2}^{2}\left(-2 R_{3}^{2} \mu_{3}-2 R_{3}^{2}\right)+2 E_{1} E_{3} R_{3}^{2} \mu_{2}^{2}-2 E_{1} E_{3} R_{3}^{2}\right)+R_{2}^{4}\left(\mu_{2}\left(E_{2}\left(E_{1}\left(2 \mu_{3}+2\right)-2 E_{3}\right)+2 E_{2} E_{3} \mu_{1}\right)\right. \\
& +E_{2}^{2}\left(2 \mu_{3}+2\right)+\mu_{1}\left(E_{2}^{2}\left(-2 \mu_{3}-2\right)+2 E_{2} E_{3}\right)+E_{2}\left(E_{1}\left(-2 \mu_{3}-2 E_{3}\right)-2 E_{1} E_{3} \mu_{2}^{2}+E_{1} E_{3}\right), \\
& a_{2}=R_{1}^{2} R_{2}^{2}\left(E_{2}^{2}\left(-2 R_{3}^{2} \mu_{3}-2 R_{3}^{2}\right)+2 E_{2} E_{3} R_{3}^{2} \mu_{2}-2 E_{2} E_{3} R_{3}^{2}\right) q \text {, } \\
& m_{2}=R_{1}^{2} R_{2}^{2}\left(E_{2}^{2}\left(-\mu_{3}-1\right)+E_{2} E_{3} \mu_{2}+E_{2} E_{3}\right) q \text {. }
\end{aligned}
$$

2.2. Mechanical Model of Composite Lining considering the In Situ Stress of Surrounding Rock. According to relevant rock mechanics theories, the gravity of the rock within 2.5 times diameter surrounding the tunnel can be ignored [19]. In this case, the horizontal rock stress can be simplified as uniform distributed stress, and the problem can be transformed into an axisymmetric stress problem. Since the load is the horizontal stress and vertical stress, the Cartesian coordinate 
system needs to be converted to polar coordinate system. The analytical expressions of radial stress and circumferential stress are given by the following equation:

$$
\begin{gathered}
\sigma_{\rho}=-\frac{1-\left(r^{2} / \rho^{2}\right)}{1-\left(r^{2} / R^{2}\right)} p, \\
\sigma_{\varphi}=-\frac{1+\left(r^{2} / \rho^{2}\right)}{1-\left(r^{2} / R^{2}\right)} p .
\end{gathered}
$$

For general tunnels, the horizontal load is $\lambda p_{0}$. The model is symmetrical, while the load is asymmetric. Therefore, this problem is solved by using the superposition principle. The vertical load can be decomposed into the following equation:

$$
\begin{aligned}
p & =\frac{1}{2}(1+\lambda) p_{0}, \\
p^{\prime} & =\frac{1}{2}(1-\lambda) p_{0},
\end{aligned}
$$

where $\lambda$ is the coefficient of lateral pressure and $p_{0}$ is the vertical pressure.

The general elastic stress state of the tunnel is decomposed into the stress concentration of two orifices, as shown in Figure 2.

2.2.1. The Solution to Stress State I. For state I, the stress distribution is axisymmetric. The solution can be simplified as a single cylinder bearing an axisymmetric load as follows:

$$
\begin{gathered}
\sigma_{\rho}=\frac{1}{2} \frac{1-\left(R_{0}^{2} / \rho^{2}\right)}{1-\left(R_{0}^{2} / R^{2}\right)}(1+\lambda) p_{0}, \\
\sigma_{\varphi}=\frac{1}{2} \frac{1+\left(R_{0}^{2} / \rho^{2}\right)}{1-\left(R_{0}^{2} / R^{2}\right)}(1+\lambda) p_{0},
\end{gathered}
$$

where $R_{0}$ is the radius of tunnel and $R$ is the radius of influence zone.

Since $R$ is much bigger than $R_{0}$, get $\left(R_{0} / R\right)=0$. Then, the above equation is as follows:

$$
\begin{aligned}
& \sigma_{\rho}=\frac{1}{2}\left(1-\frac{R_{0}^{2}}{\rho^{2}}\right)(1+\lambda) p_{0}, \\
& \sigma_{\varphi}=\frac{1}{2}\left(1+\frac{R_{0}^{2}}{\rho^{2}}\right)(1+\lambda) p_{0} .
\end{aligned}
$$

2.2.2. The Solution to Stress State II. For state II, the stress distribution can be regarded as the problem of orifice stress concentration. The upper and lower sides of the model are under uniform pressure, while the left and right sides are under uniform tension. Because the great circle is outside the influence radius of excavation, the stress boundary at the great circle is the same as that without holes. Thus, there are $\sigma_{x}=-p^{\prime}$ and $\sigma_{y}=p^{\prime}$. The outer boundary of the hole wall can be obtained by coordinate transformation.

$$
\begin{gathered}
\left(\sigma_{\rho}\right)_{\rho=R}=-p^{\prime} \cos 2 \varphi, \\
\left(\tau_{\rho \varphi}\right)_{\rho=R}=p^{\prime} \sin 2 \varphi .
\end{gathered}
$$

The inner boundary conditions of the hole wall are as follows:

$$
\begin{gathered}
\left(\sigma_{\rho}\right)_{\rho=r}=0, \\
\left(\tau_{\rho \varphi}\right)_{\rho=r}=0 .
\end{gathered}
$$

Using the semi-inverse solution method in elastic mechanics and taking the boundary conditions into consideration, the stress function is only related to $\rho$ and $2 \theta$. Therefore, take the stress function as follows:

$$
\Phi=f(\rho) \cos 2 \varphi .
$$

The general solution of the stress function can be obtained by substituting into the compatible equation as follows:

$$
\Phi=\cos 2 \varphi\left(A \rho^{4}+B \rho^{4}+C+\frac{D}{\rho^{2}}\right) .
$$

According to the boundary conditions, the coefficients are as follows:

$$
\begin{aligned}
& A=0, \\
& B=\frac{p^{\prime}}{2}, \\
& C=p^{\prime} R_{0}^{2}, \\
& D=\frac{1}{2} p^{\prime} R_{0}^{4} .
\end{aligned}
$$

Finally, the stress solution under this circumstance can be obtained as follows:

$$
\begin{aligned}
& \sigma_{\rho}=p^{\prime} \cos 2 \varphi\left(1-4 \frac{R_{0}^{2}}{\rho^{2}}+3 \frac{R_{0}^{4}}{\rho^{4}}\right) \\
& \sigma_{\varphi}=p^{\prime} \cos 2 \varphi\left(1+3 \frac{R_{0}^{4}}{\rho^{4}}\right) \\
& \tau_{\rho \varphi}=p^{\prime} \sin 2 \varphi\left(1+2 \frac{R_{0}^{2}}{\rho^{2}}-3 \frac{R_{0}^{4}}{\rho^{4}}\right)
\end{aligned}
$$

Therefore, the total stress solution under the in situ stress of surrounding rock can be obtained as follows: 


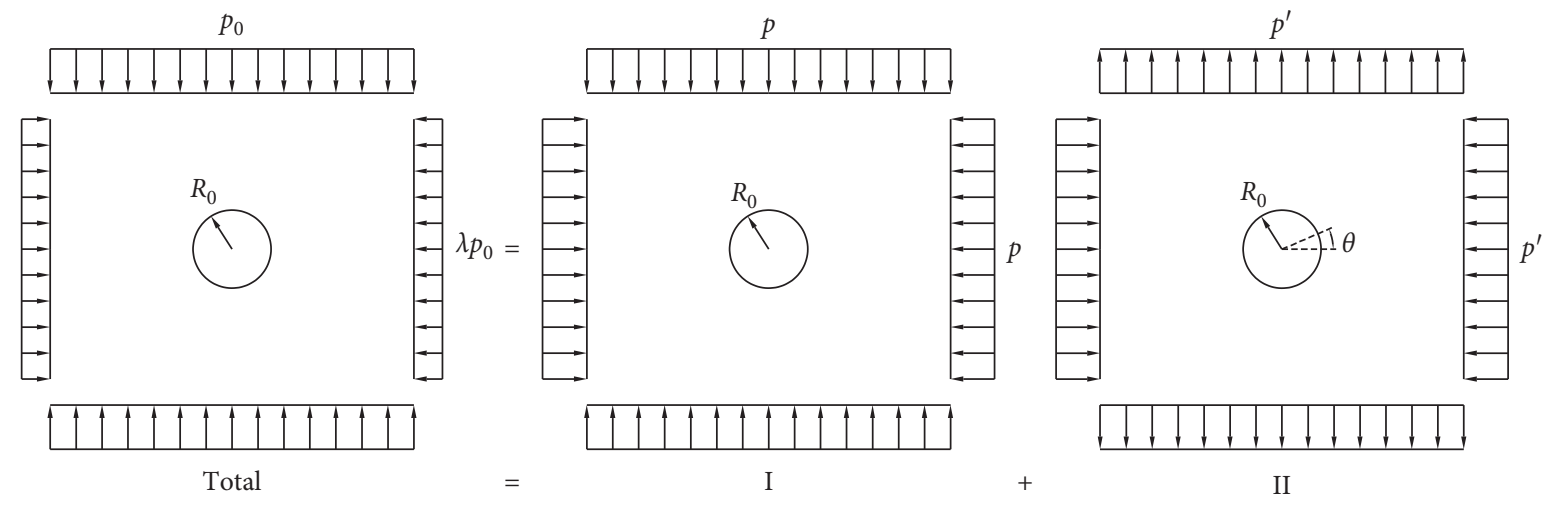

FIgURE 2: General method of stress state decomposition in tunnel.

$$
\begin{aligned}
\sigma_{\rho}= & \frac{1}{2}\left(1-\frac{R_{0}^{2}}{\rho^{2}}\right)(1+\lambda) p_{0}-\frac{1}{2}(1-\lambda) p_{0} \\
& \cdot \cos 2 \varphi\left(1-4 \frac{R_{0}^{2}}{\rho^{2}}+3 \frac{R_{0}^{4}}{\rho^{4}}\right), \\
\sigma_{\varphi}= & \frac{1}{2}\left(1+\frac{R_{0}^{2}}{\rho^{2}}\right)(1+\lambda) p_{0}+\frac{1}{2}(1-\lambda) p_{0} \cos 2 \varphi\left(1+3 \frac{R_{0}^{4}}{\rho^{4}}\right), \\
\tau_{\rho \varphi}= & \frac{1}{2}(1-\lambda) p_{0} \sin 2 \varphi\left(1+2 \frac{R_{0}^{2}}{\rho^{2}}-3 \frac{R_{0}^{4}}{\rho^{4}}\right),
\end{aligned}
$$

where $\sigma_{\rho}$ is the radial stress, $\sigma_{\varphi}$ is the circumferential stress, and $\tau_{\rho \varphi}$ is the tangential stress.

\section{A Case Study}

3.1. Engineering Background. As a strategic project in China, the SNWDP is an oversized infrastructure project to solve the serious shortage of water resources in northern China and implement optimal allocation of water resources. The project plays a crucial role in reducing the bearing pressure of water resources and improving the guarantee rate of water supply security. The Eastern Canal in Beijing was constructed using composite lining method, and the water conveyance tunnel was subjected to in situ stress and water pressure for a long time.

Composite lining structure was adopted for deep buried water conveyance tunnel, as shown in Figure 3. The outer lining was made of precast concrete tubes with a thickness of $300 \mathrm{~mm}$ and the label is C50/W10/F150. The outer diameter of the tube piece was $6 \mathrm{~m}$, the inner diameter was $5.4 \mathrm{~m}$, and the width of the tube piece was $2 \mathrm{~m}$. Each ring piece was composed of three types of pipe pieces, i.e., $A, B$, and $C$. The joints of the tube pieces were connected with bent bolts, sixteen M24 bolts for each ring seam and twelve M24 bolts for each longitudinal seam. An ethylene-propylene-diene monomer elastic rubber gasket was used for waterproof between the lining tube segments. The outside of the gasket was provided with water-repellent strip, a water swelling rubber. The inner lining was a circular section, adopting

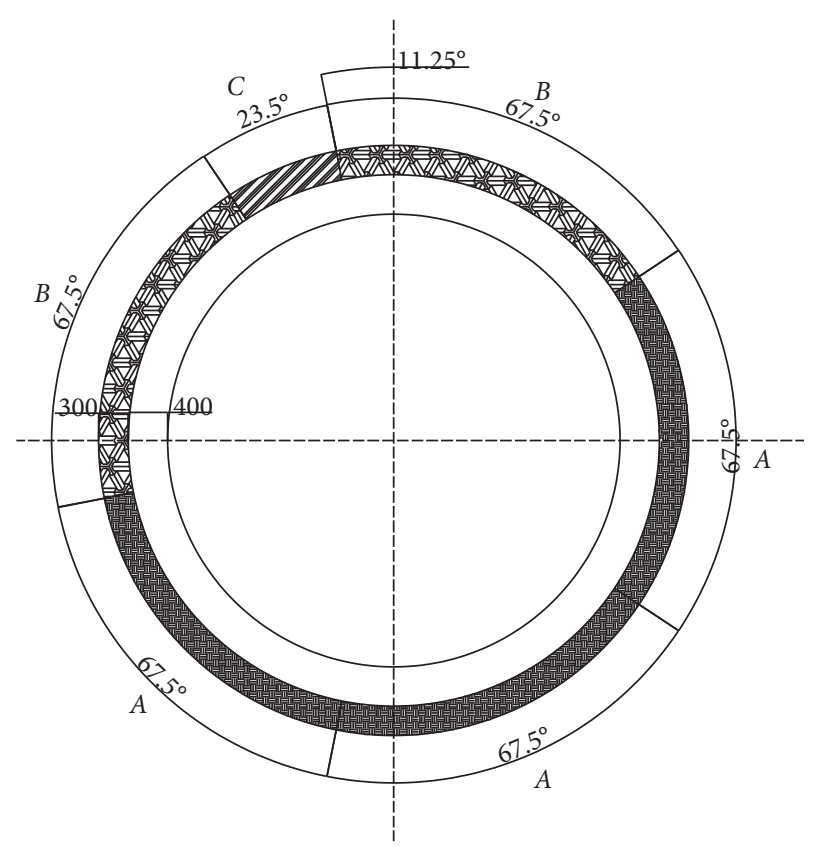

FIgURE 3: Schematic diagram of composite lining for water conveyance tunnel.

one-time concreting shaping technology when constructed. The inner diameter of the inner lining was $4.6 \mathrm{~m}$ and the thickness was $400 \mathrm{~mm}$, pouring with C35/W6/F150 selfcompacting concrete.

In this study, Pile No. $28+859$ and surrounding areas of Eastern Canal for the SNWDP were selected. Then, the simplified algorithm method and the finite element method using ABAQUS for composite lining were adopted to calculate the stress distribution, respectively. And a comparison was made.

\subsection{Analysis of Composite Lining by Simplified Algorithm}

3.2.1. Material Parameters. According to relevant geological report, there are seven types of strata in the section of Pile No. $28+859$. A geological model containing seven different materials was established, as shown in Figure 4. The parameters of each layer are shown in Table 1. 


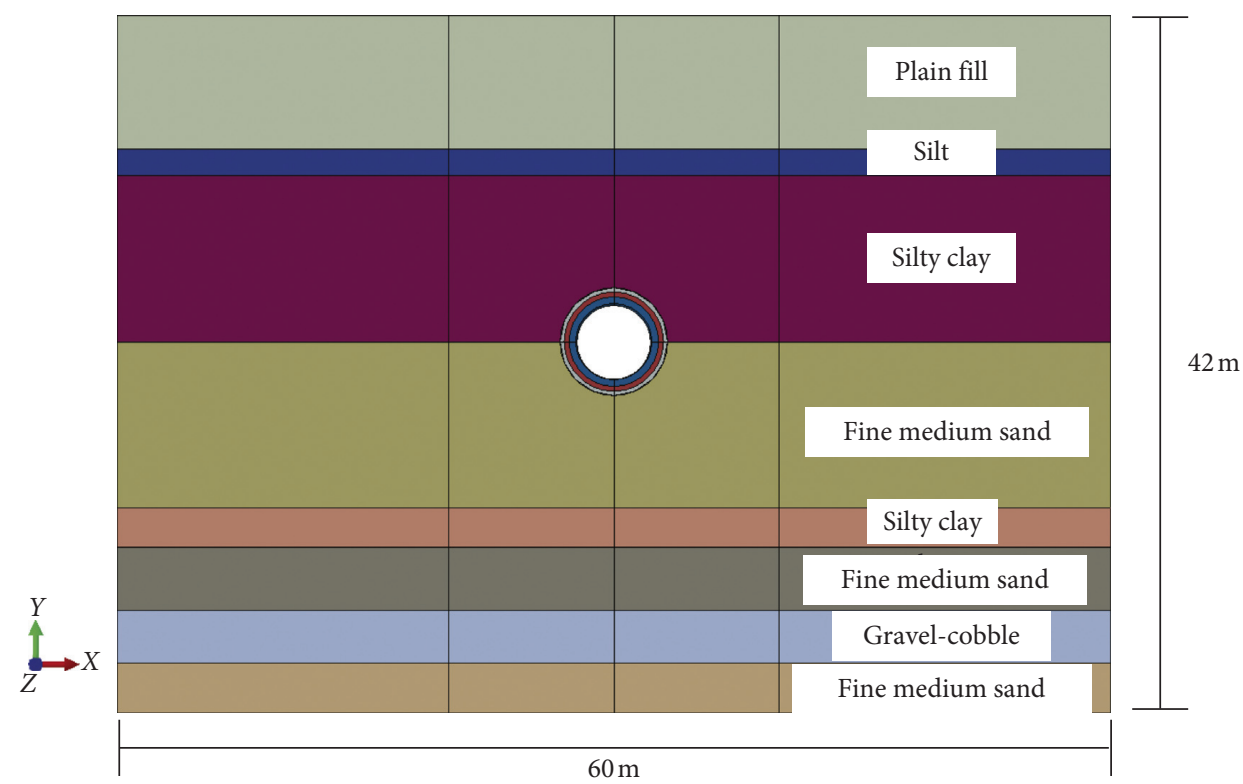

FIgURE 4: Formation model of the area around Pile No. $28+859$.

TABLE 1: Local layer parameters.

\begin{tabular}{lccccc}
\hline Number & Stratum & Density $\left(10^{3} \mathrm{~kg} / \mathrm{m}^{3}\right)$ & Elasticity modulus $(\mathrm{MPa})$ & Poisson's ratio & Thickness $(\mathrm{m})$ \\
\hline 1 & Plain fill & 1.60 & 3.8013 & 0.35 & 3.00 \\
2 & Silt & 1.97 & 5.2993 & 0.29 & 0.30 \\
3 & Silty clay & 2.02 & 5.9763 & 0.20 & 3.80 \\
4 & Fine medium sand & 2.03 & 22.5000 & 0.30 & 2.36 \\
5 & Silty clay & 2.02 & 20.4585 & 0.25 & 10.00 \\
6 & Fine medium sand & 2.05 & 25.0000 & 0.15 & 10.00 \\
7 & Gravel-cobble & 2.10 & 33.1470 & 0.28 & 8.05 \\
8 & Silty clay & 1.98 & 10.9773 & & 8.05 \\
\hline
\end{tabular}

The concrete of the outer lining for water conveyance tunnel is C50, and the inner lining concrete is C35. According to the code for the design of concrete structures, the elastic modulus of C50 concrete is $34.5 \mathrm{GPa}$ and Poisson's ratio is 0.2 . The elastic modulus of C35 concrete is $31.5 \mathrm{GPa}$, and Poisson's ratio is 0.2 . The density of concrete is $2400 \mathrm{~kg} / \mathrm{m}^{3}$. The model of outer lining and inner lining adopts the linear elastic constitutive model.

The reinforcement grade of the inner lining and outer lining is HRB335. The elastic modulus of reinforcement is $200 \mathrm{GPa}$, and the density is $7.85 \mathrm{~g} / \mathrm{cm}^{3}$.

The material properties of reinforced concrete are obtained by the equivalent modulus method as shown in equation (28) [20]. The volume reinforcement ratio is 0.0238 for the outer lining and 0.0195 for the inner lining.

$$
E_{o}=E_{s} \rho+E_{c}(1-\rho),
$$

where $E_{0}$ is the elasticity modulus, $E_{s}$ is the elasticity modulus of reinforcement, $E_{c}$ is the elasticity modulus of concrete, and $\rho$ is the ratio of reinforcement.

Finally, the elastic modulus and Poisson's ratio of outer lining are $38.5 \mathrm{GPa}$ and 0.2 , respectively. The elastic modulus of inner lining is $34.8 \mathrm{GPa}$, and Poisson's ratio is 0.2 . The density of both is $2400 \mathrm{~kg} / \mathrm{m}^{3}$.

3.2.2. Stress of Composite Lining under Internal Pressure. The hydraulic pressure condition of the water conveyance tunnel was set to $35 \mathrm{~m}$. Finally, the expression of stress function was obtained, as shown in equations (29) and (30). Since the water conveyance tunnel is a plane strain problem, the elastic modulus should be changed to $E /\left(1-\mu^{2}\right)$ and Poisson's ratio should be changed to $\mu /(1-\mu)$. The coefficients are obtained as shown in Table 2.

Therefore, the stress distribution of the outer lining under the action of internal water pressure can be obtained as follows:

$$
\begin{aligned}
& \sigma_{\rho}=-\frac{4.3428 \times 10^{6}}{\rho^{2}}+4.7096 \times 10^{5}, \\
& \sigma_{\varphi}=\frac{4.3428 \times 10^{6}}{\rho^{2}}+4.7096 \times 10^{5}, \\
& \tau_{\rho \varphi}=\tau_{\varphi \rho}=0 .
\end{aligned}
$$


TABLE 2: Stress coefficients under internal pressure.

\begin{tabular}{cccccccc}
\hline$A_{1}$ & $B_{1}$ & $C_{1}$ & $A_{2}$ & $B_{2}$ & $C_{2}$ & $A_{3}$ & $B_{3}$ \\
\hline$-4.3428 \times 10^{6}$ & 0 & $2.3548 \times 10^{5}$ & $-4.7683 \times 10^{6}$ & 0 & $2.6466 \times 10^{5}$ & $-4.4571 \times 10^{3}$ & 0 \\
\hline
\end{tabular}

The stress of the inner lining is as follows:

$$
\left.\begin{array}{l}
\sigma_{\rho}=-\frac{4.7683 \times 10^{6}}{\rho^{2}}+5.2932 \times 10^{5} \\
\sigma_{\varphi}=\frac{4.7683 \times 10^{6}}{\rho^{2}}+5.2932 \times 10^{5} \\
\tau_{\rho \varphi}=\tau_{\varphi \rho}=0
\end{array}\right\} .
$$

The distribution of radial and circumferential stresses under internal pressure is shown in Figures 5 and 6. Under internal pressure, the maximum circumferential stress of inner lining was greater than that of the outer lining. Only radial stress was transferred between the outer lining and inner lining. With the increase of radius, both radial stress and circumferential stress gradually decreased. The maximum radial stress was $0.35 \mathrm{MPa}$, and the maximum circumferential stress was $1.29 \mathrm{MPa}$.

3.2.3. Stress of Composite Lining under the In Situ Stress of Surrounding Rock. When the composite lining was under the in situ stress of the surrounding rock, the vertical pressure of overburden was calculated by means of the summation of layers, as shown in the following equation:

$$
p_{0}=\sum_{i=1}^{n} \gamma_{i} h_{i}=26.24 \mathrm{kPa}
$$

According to the empirical formula (equation (32)), the lateral pressure coefficient can be calculated as $0.25, \lambda=0.25$.

$$
\lambda=\frac{\mu}{(1-\mu)}
$$

So, the stress of the composite lining under the action of overburdening is as follows:

$$
\begin{aligned}
\sigma_{\rho} & =16400\left(1-\frac{5.29}{\rho^{2}}\right)-9840 \cos 2 \varphi\left(1-\frac{21.16}{\rho^{2}}+\frac{83.95}{\rho^{4}}\right), \\
\sigma_{\varphi} & =16400\left(1+\frac{5.29}{\rho^{2}}\right)+9840 \cos 2 \varphi\left(1+\frac{83.95}{\rho^{4}}\right), \\
\tau_{\rho \varphi} & =9840 \sin 2 \varphi\left(1+\frac{10.58}{\rho^{2}}-\frac{83.95}{\rho^{4}}\right) .
\end{aligned}
$$

According to this equation, the tunnel has a maximum compressive stress in the horizontal direction $\left(\theta=0^{\circ}\right.$ and $\left.\theta=180^{\circ}\right)$ and a minimum stress in the vertical direction $\left(\theta=90^{\circ}\right.$ and $\left.\theta=270^{\circ}\right)$. There is a tensile stress on the vertical axis.

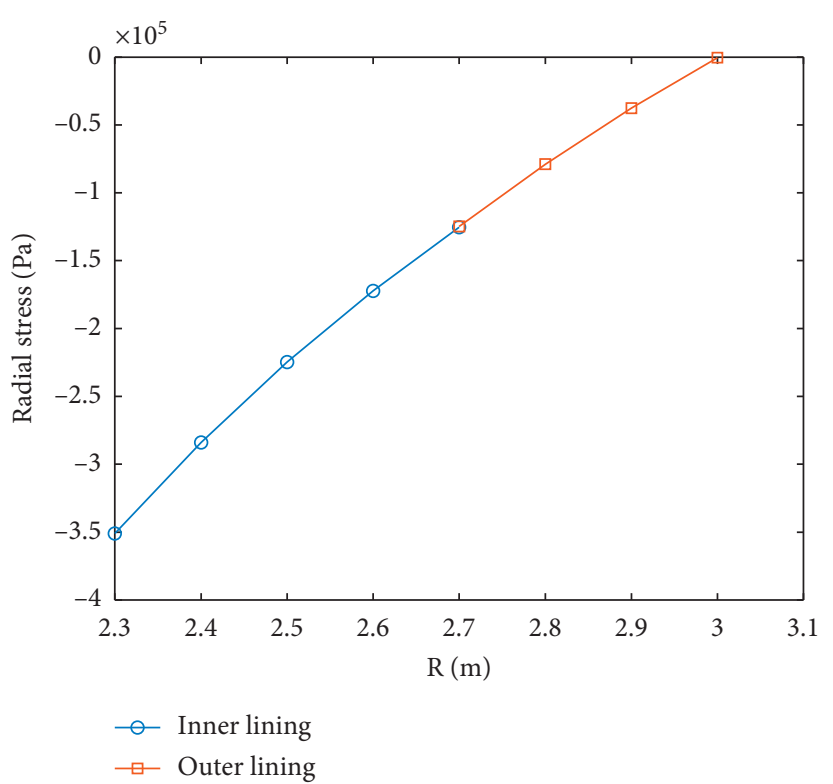

FIgURE 5: Distribution of radial stress under internal pressure.

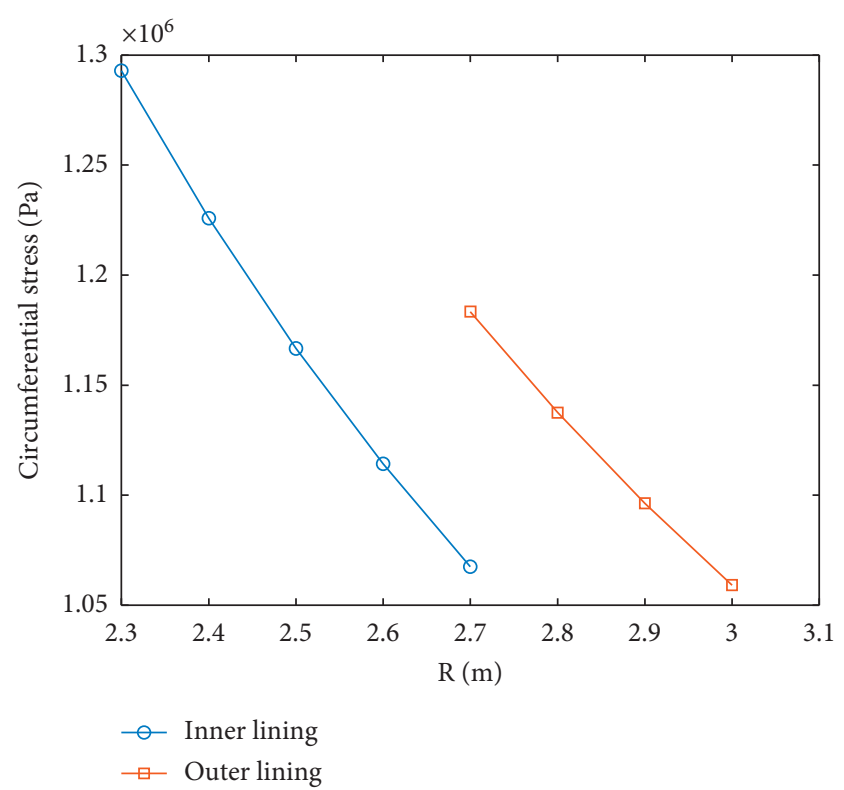

FIgURE 6: Distribution of circumferential stress under internal pressure.

The distribution of radial stress and circumferential stress under surrounding rock is shown in Figures 7 and 8. Under the in situ stress of surrounding rock, as for the direction of $\theta=0^{\circ}$, with the increase of radius, the radial stress distribution first increases and then decreases. There is the maximum radial stress at $1.5 R$. For other directions, the radial stress distribution first increases and then gradually 


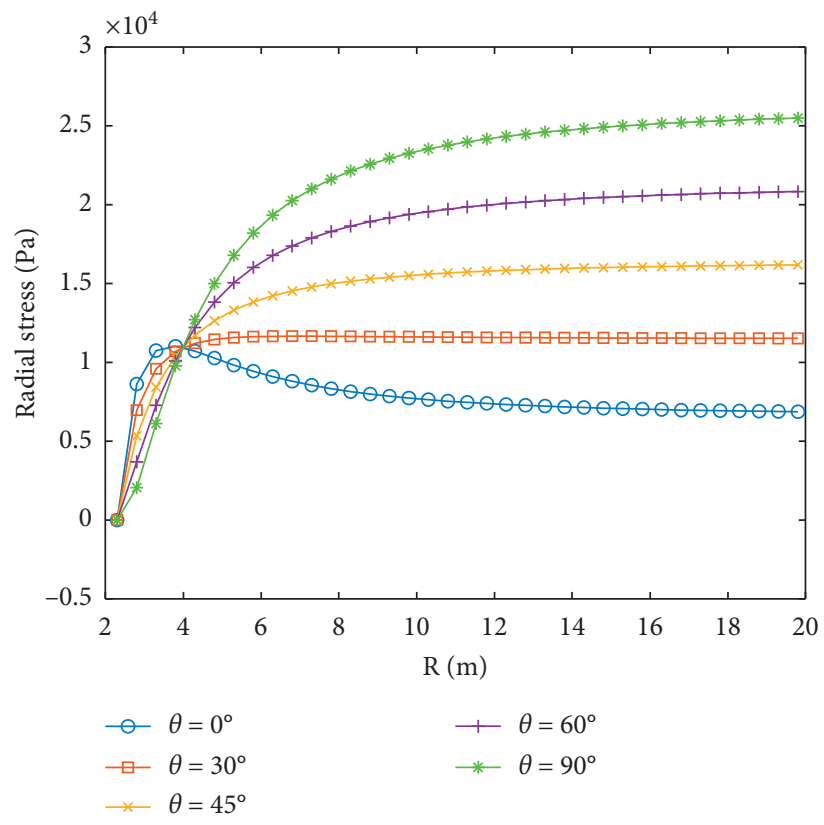

Figure 7: Radial stress at every angle under the in situ stress of surrounding rock.

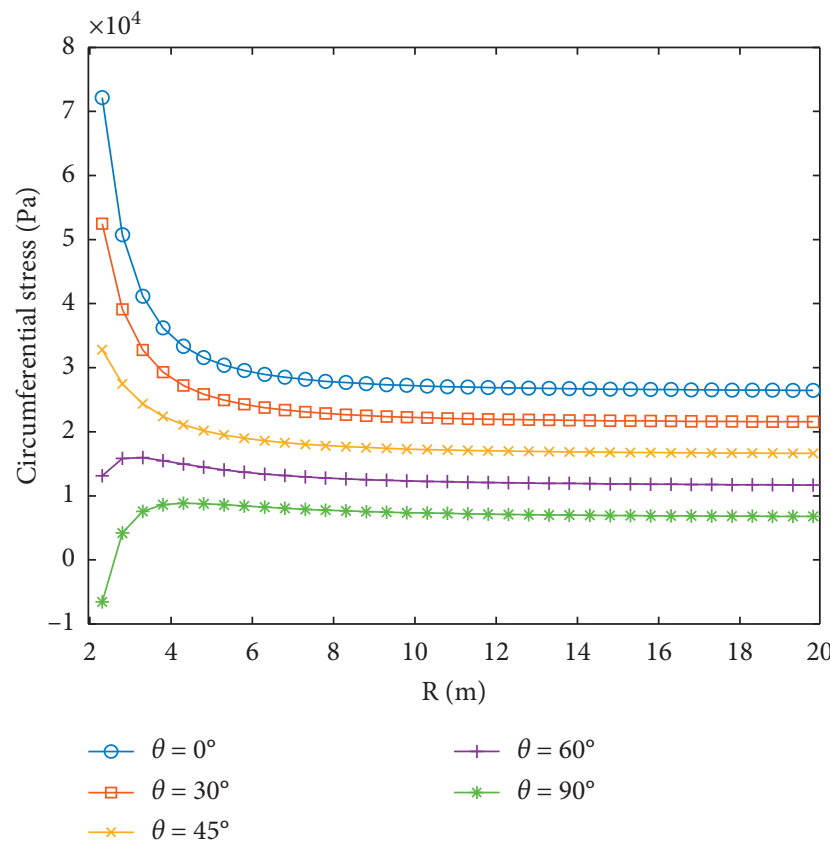

Figure 8: Circumferential stress under the in situ stress of surrounding rock.

tends to be stable and is unaffected beyond $5 R$. For circumferential stress, there is the maximum compressive stress at $\theta=0^{\circ}$. As the angle increases, the stress decreases gradually. In addition, when the lateral pressure coefficient is equal to 0.25 , tensile stress is generated at $\theta=90^{\circ}$.
Under the internal water pressure and the in situ stress of surrounding rock, the total radial and circumferential stresses in the horizontal and vertical directions of the inner and outer lining are finally obtained, as shown in Table 3.

The distribution of radial stress and circumferential stress under the internal water pressure and the in situ stress of surrounding rock is shown in Figures 9 and 10. As can be seen from the two figures, the circumferential stress in the vertical direction is higher than that in horizontal direction due to the in situ stress of surrounding rock. The stress distribution of composite lining is mainly affected by the high internal water pressure. Besides, the stress of inner lining is higher than that of outer lining. They share the load together.

\subsection{Analysis of Composite Lining by ABAQUS}

3.3.1. Finite Element Model Establishment and Calculation Procedure. In this paper, a large-scale finite element calculation software ABAQUS is used to carry out the threedimensional simulation of the entire construction process around Pile No. $28+859$ in the Eastern Canal of the SNWDP. Considering the influence range of the tunnel $[21,22]$, the length and width of the numerical model established are $60 \mathrm{~m}$ and $42 \mathrm{~m}$, respectively. The surface of the model is horizontal and is a free boundary. Normal displacement constraint boundary is applied to the side of the model, and fixed constraint boundary is applied to the bottom of the model. The numerical model is shown in Figure 11. 
TABLE 3: Radial and circumferential stresses on the horizontal axis (MPa).

\begin{tabular}{lcccc}
\hline \multirow{2}{*}{ Stress direction } & \multicolumn{2}{c}{ Inner lining } & \multicolumn{2}{c}{ Outer lining } \\
& Horizontal axis & Vertical axis & Horizontal axis & Vertical axis \\
\hline Radial stress & -0.350 & -0.350 & -0.132 & -0.126 \\
Circumferential stress & 1.220 & 1.300 & 1.130 & 1.180 \\
\hline
\end{tabular}

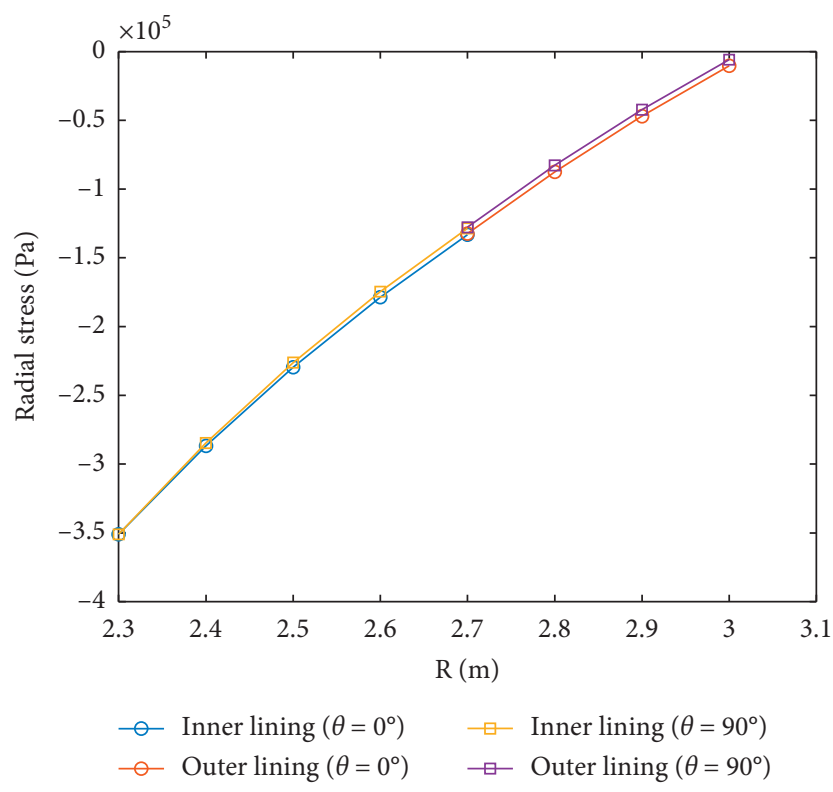

FIGURE 9: Distribution of radial stresses under internal pressure and in situ stress of surrounding rock.

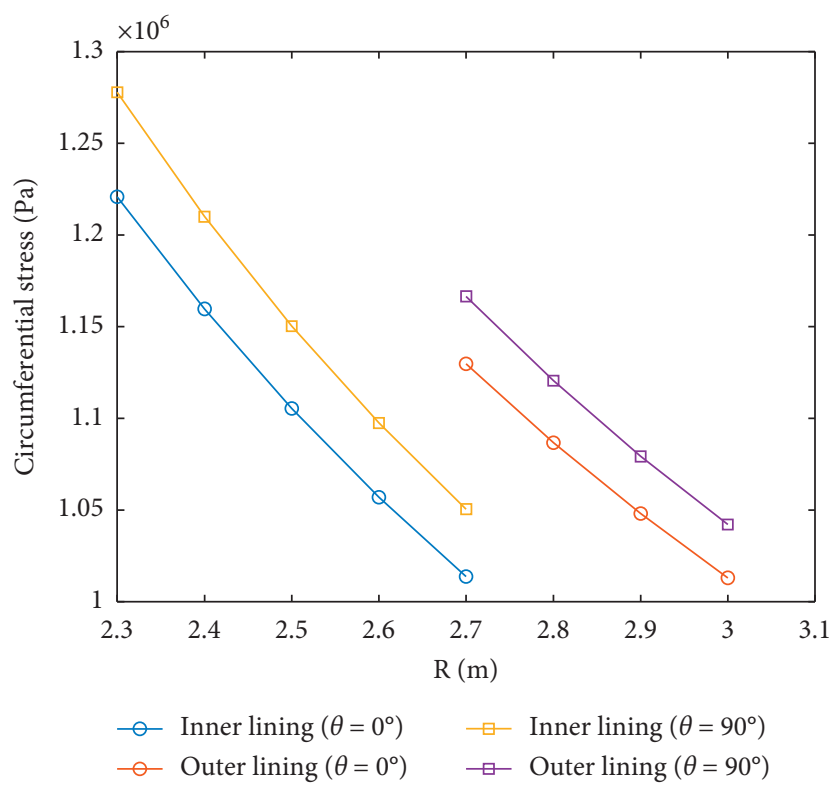

FIGURE 10: Distribution of circumferential stress under internal pressure and in situ stress of surrounding rock. 


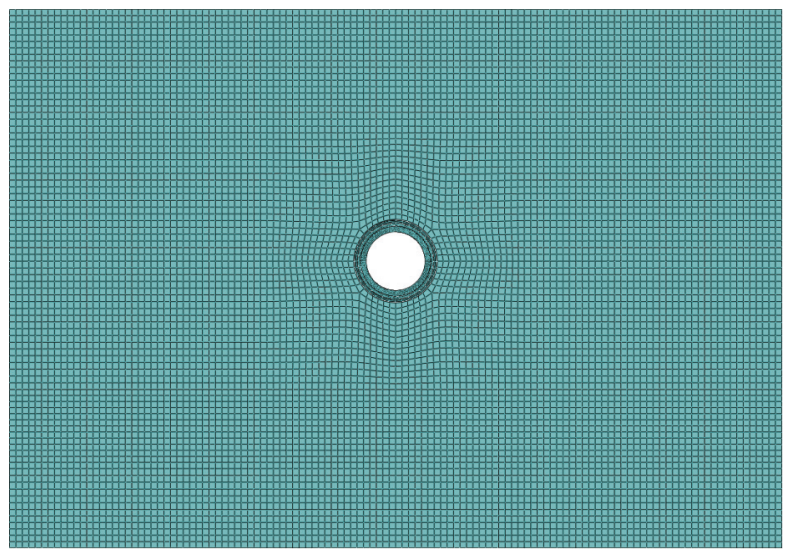

FIgURE 11: Numerical model of the area around Pile No. $28+859$.

The stratum and lining structure in this numerical model are modelled by solid elements. In the construction of shield tunnelling, there will be a shield tail gap [23], which consists of three parts: the volume occupied by the thickness of the shield shell, the operation clearance reserved for the convenience of lining assembly, and the overcut clearance. In the numerical analysis, it is very difficult to quantify the factors, such as the gap size of the shield tail, grouting filling degree, and disturbance degree of the stratum around the shield wall. Therefore, they can be generalized as homogeneous, isopachous, and elastic equivalent circle, as shown in Figure 12. The thickness of equivalent circle is given by the following equation:

$$
\delta=\eta A
$$

where $A$ is the shield tail gap; it is half the difference between the outside diameter of the shield and that of the lining.

The shell diameter of shield tunnelling machine in this research was $6.25 \mathrm{~m}$, and the lining outside diameter was $6 \mathrm{~m}$, so $A=125 \mathrm{~mm}$. In this model, the thickness of the equivalent circle was $250 \mathrm{~mm}$ and Poisson's ratio was 0.2. The density of the equivalent circle was $2100 \mathrm{~kg} / \mathrm{m}^{3}$ by using the density of cement mortar. The elastic modulus was obtained by parameter inversion, which was done using the measured surface subsidence data. Then, the elastic modulus of equivalent circle was $20 \mathrm{MPa}$.

In this simulation, each construction process of composite lining method was taken as the analysis step, and each calculation step can be simplified as follows:

(1) Balancing initial in situ stress field (the calculated load included the gravity of each stratum).

(2) Carrying out tunnel excavation, pipe piece assembly, and grouting (the calculated load included excavation unloading and the weight of the pipe).
(3) Pouring concrete inner lining and applying the internal water pressure.

3.3.2. Calculation Results of the Finite Element Model. The $35 \mathrm{~m}$ inner water pressure was applied to the lining in the calculation. The finite element calculation results are shown in Figures 13-15. It can be seen from the results that the surrounding rock stress is disturbed and the stress level is increased. Both the inner and outer linings are subjected to tensile forces. The maximum circumferential tensile stress is 1.261 MPa and is located at the inner boundary of the lining. The calculated results are consistent with the analytic solution of the simplified algorithm.

The radial and circumferential stresses in the horizontal and vertical axis directions of the inner and outer linings are finally obtained, as shown in Table 4.

The comparison between Tables 3 and 4 shows that the composite lining simplified calculation method is basically consistent with the finite element calculation results. When the water pressure is under $35 \mathrm{~m}$, the lining is subjected to tensile stress across the whole section. There is a large tensile stress inside the lining, and the stress gradually decreases along the radius direction, which is also consistent with the calculation result of the simplified calculation method. The inner lining stress level is greater than that of outer lining. According to the numerical simulation results, the stress of horizontal direction $\left(\theta=0^{\circ}\right.$ and $\theta=180^{\circ}$ ) is small, the stress of inner lining is $1.201 \mathrm{MPa}$, and the stress of outer lining is $1.141 \mathrm{MPa}$. The stress of vertical direction $\left(\theta=90^{\circ}\right.$ and $\left.\theta=270^{\circ}\right)$ is small, the stress of inner lining is $1.262 \mathrm{MPa}$, and the stress of outer lining is $1.146 \mathrm{MPa}$. Due to the influence of surrounding rock, the maximum compressive stress turns up in the horizontal direction. Therefore, the force on the horizontal axis is less than that on the vertical axis. 


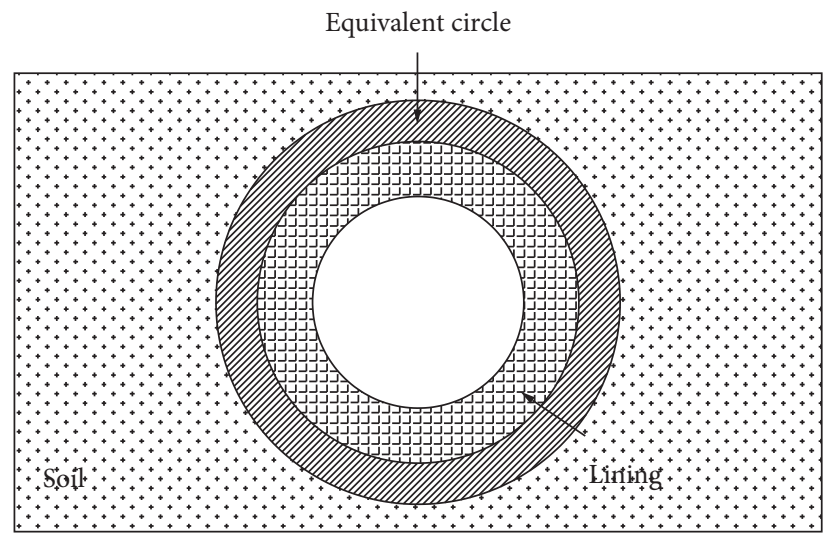

FIGURE 12: Sketch map of equivalent circle.

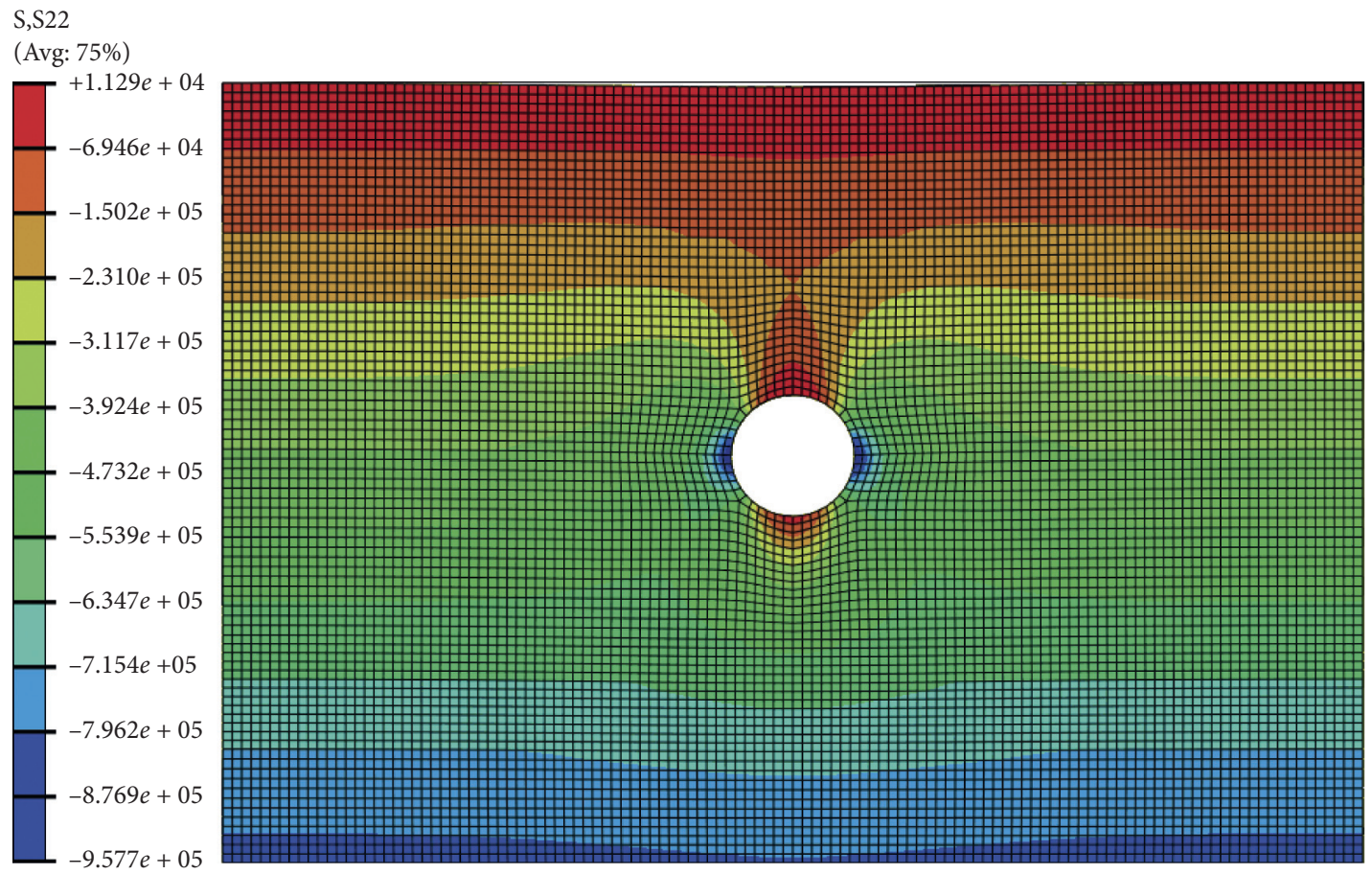

Figure 13: Vertical stress distribution of surrounding rock $(\mathrm{Pa})$.

S, S11 (CSYS-1)

(Avg: $75 \%$ )

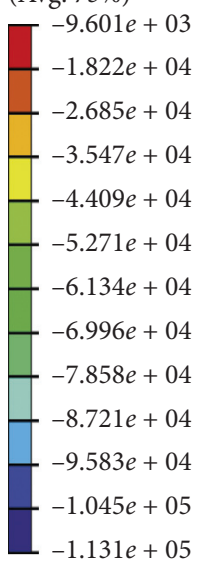

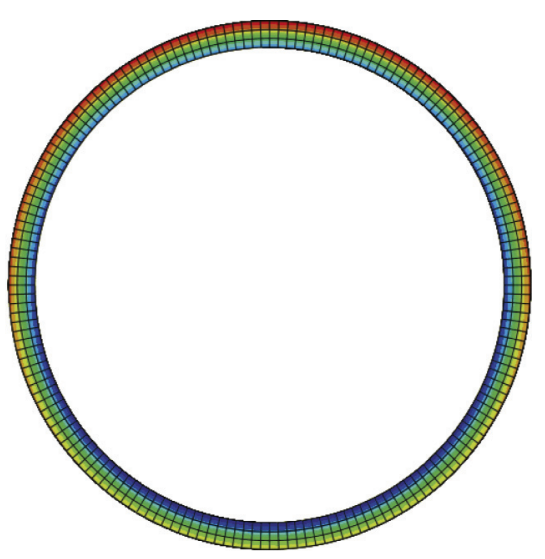

(a)
S, S22 (CSYS-1) (Avg: $75 \%$ )
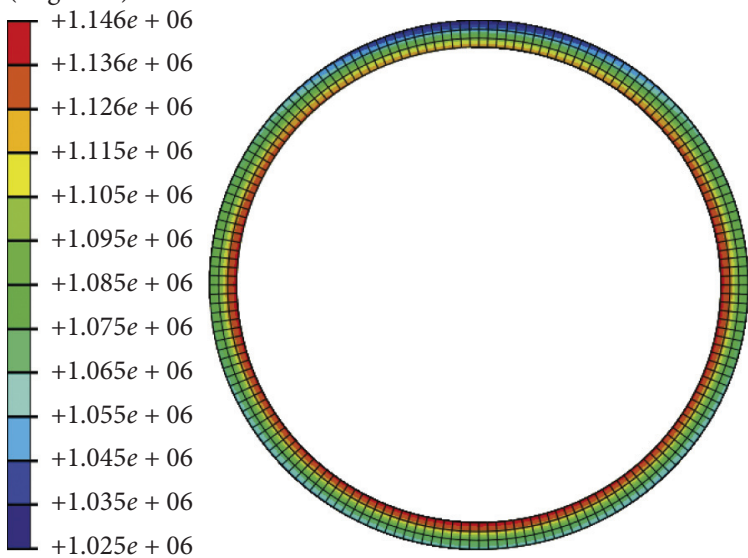

(b)

Figure 14: Radial stress (a) and circumferential stress of outer lining (b) (Pa). 


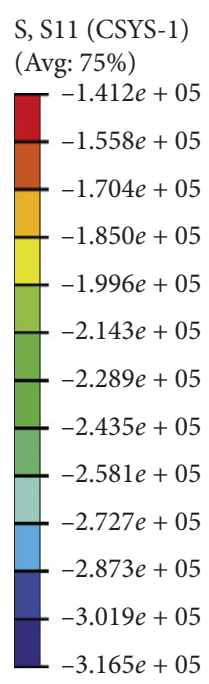

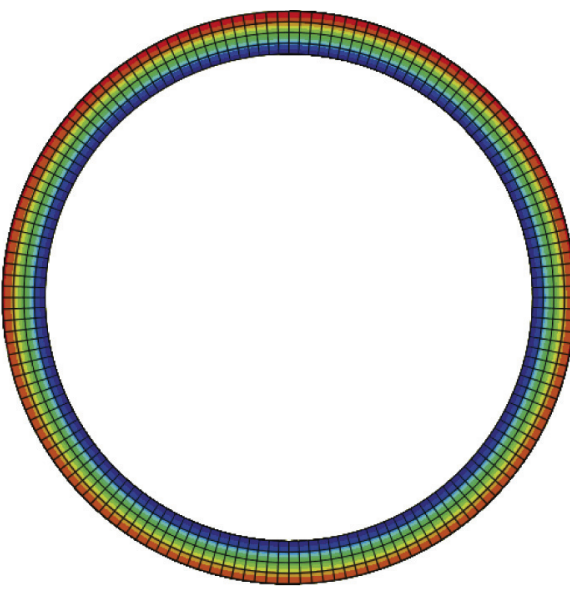

(a)

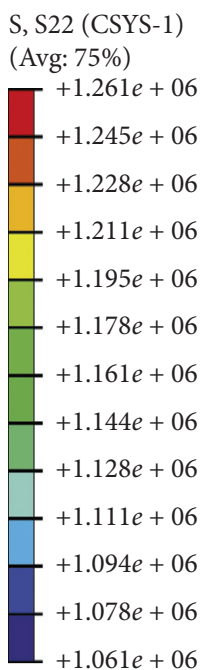

$+1.061 e+06$

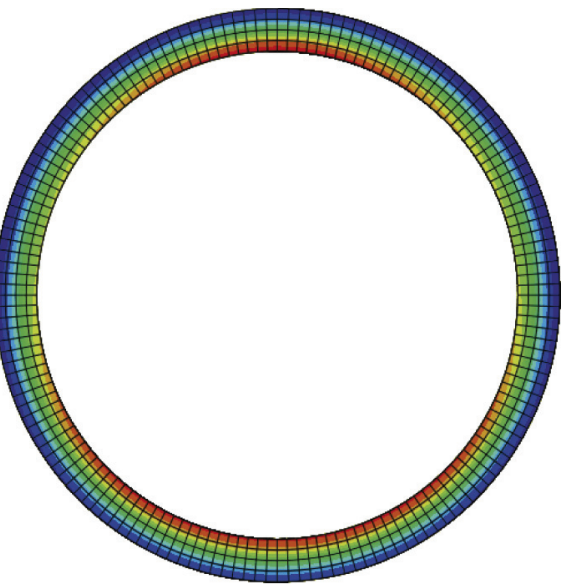

(b)

Figure 15: Radial stress (a) and circumferential stress of inner lining (b) (Pa).

TABLE 4: Results of finite element calculation (MPa).

\begin{tabular}{lcccc}
\hline \multirow{2}{*}{ Stress direction } & \multicolumn{2}{c}{ Inner lining } & \multicolumn{2}{c}{ Outer lining } \\
& Horizontal axis & Vertical axis & Horizontal axis & Vertical axis \\
\hline Radial stress & -0.316 & -0.315 & -0.104 & -0.113 \\
Circumferential stress & 1.201 & 1.262 & 1.141 & 1.146 \\
\hline
\end{tabular}

\section{Conclusion}

(1) In this paper, a simplified algorithm is presented to calculate the mechanical response of composite lining under the internal pressure and surrounding rock. When the composite lining is bearing inner water pressure, the model is simplified as a doublelayer cylinder buried in a semi-space infinite body, and the analytical solution is obtained, taking into consideration the corresponding boundary conditions. When the composite lining is under the in situ stress of surrounding rock, the model is described as the stress concentration problem of small holes. Through the superposition of the two results, the simplified algorithm of composite lining is obtained.

(2) According to the calculated results, when subjected to the in situ stress of surrounding rock, the composite lining has the maximum compressive stress on the horizontal axis and the minimum stress on the vertical axis. And there is a tensile stress on the vertical axis. When the inner high water pressure is applied, the inner lining stress level is higher than that of outer lining, and it is the tensile stress. When the in situ stress of surrounding rock and internal pressure are superimposed, the composite lining is subjected to tensile stress. The stress on the horizontal axis is less than that on the vertical axis, the circumferential stress of the inner lining is $1.220 \mathrm{MPa}$ and that of the outer lining is $1.113 \mathrm{MPa}$ in the horizontal direction, and the circumferential stress of the inner lining in the vertical direction is $1.300 \mathrm{MPa}$ and that of the outer lining is 1.180 MPa. Besides, the analytical solution is basically consistent with the results of finite element method, proving the correctness and feasibility of the composite lining simplified algorithm.

(3) Currently, most of the calculation methods at home and abroad are too conservative, which results in high project cost. In addition, the calculation results differ greatly, and the process is relatively complex. The simplified algorithm of composite lining proposed in this paper has the advantage of high precision and efficiency and low computational resource cost. The simplified algorithm has a high generalization performance and can be used as a reference for other engineering designs.

\section{Data Availability}

The data used to support the findings of this study are included within the article.

\section{Conflicts of Interest}

The authors declare that there are no conflicts of interest regarding the publication of this paper. 


\section{Acknowledgments}

This study was financially supported by the National Key Research and Development Program of China (grant no. 2017YFC1503104).

\section{References}

[1] M. J. Zhai, Y. S. Fu, and Y. Han, "Structural type analysis of the lining tunnel of Beijing south-to-north water diversion project," People's Yellow River, vol. 37, no. 12, pp. 96-98, 2015.

[2] F. Yang, S. Cao, and G. Qin, "Performance of the prestressed composite lining of a tunnel: case study of the Yellow River crossing tunnel," International Journal of Civil Engineering, vol. 16, no. 2, pp. 229-241, 2018.

[3] M. Q. Xiao, S. F. Wang, Y. F. Gong et al., "Discussion on the structural design of shield tunnel segments," Railway Standard Design, vol. 63, no. 9, pp. 70-73, 2019.

[4] Civil Society, Tunnel Standards and Specifications [Shield] and Interpretation, China Building Industry Press, Beijing, China, 2011.

[5] B. Sun, H. L. Fu, and J. B. Zhang, "Internal force analysis of underwater shield tube based on modified idiomatic method," Journal of Railway Science and Engineering, vol. 13, no. 5, pp. 929-937, 2016.

[6] Y. C. Peng, W. Q. Ding, Z. G. Yan et al., "Analysis and calculation method of influencing factors of bending stiffness efficiency in conventional method," Journal of Geotechnical Engineering, vol. 35, no. S1, pp. 495-500, 2013.

[7] C. S. Pan, "Guide for lining design of shield tunnel (draft)," World Tunnel, vol. 2, pp. 19-29, 1997.

[8] M. Q. Xiao, K. Feng, C. Li et al., "Research on the calculation method of surrounding rock pressure of shield tunnelling in composite formation," Journal of Rock Mechanics and Engineering, vol. 38, no. 9, pp. 1836-1847, 2019.

[9] D. Y. Zeng and C. He, "Comparative analysis and research of internal force calculation method of shield tunnel lining structure," Journal of Underground Space and Engineering, vol. 5, pp. 707-712, 2005.

[10] N.-A. Do, D. Dias, P. Oreste, and I. Djeran-Maigre, “2D tunnel numerical investigation: the Influence of the simplified excavation method on tunnel behaviour," Geotechnical and Geological Engineering, vol. 32, no. 1, pp. 43-58, 2014.

[11] B. Geng, X. Y. Wen, K. Su et al., "Research on the beamspring-contact model for the internal force analysis of TBM tunnel tube sheet lining," Journal of Underground Space and Engineering, vol. 14, no. S2, pp. 660-666, 2018.

[12] X. Z. Shen, J. C. Duan, C. Y. Xu et al., "Research on mechanical characteristics of double-layer lining structure of shield tunnel based on beam-nonlinear spring model," Railway Standard Design, vol. 64, no. 12, pp. 108-113+119, 2020.

[13] W. Zhu, R. J. HU, and X. C. Zhong, "Comparison of several design methods of shield tunnel segments," Underground Space, vol. 4, pp. 352-356, 2003.

[14] Working Group No. 2, International Tunnelling Association, "Guidelines for the design of shield tunnel lining," Tunnelling and Underground Space Technology, vol. 15, no. 3, pp. 303$331,2000$.

[15] H. El Naggar and S. D. Hinchberger, "An analytical solution for jointed tunnel linings in elastic soil or rock," Canadian Geotechnical Journal, vol. 45, no. 11, pp. 1572-1593, 2008.

[16] C. B. Xu, Simplified Calculation Method and Finite Element Method of Composite Lining Shield Water Conveyance Tunnel,
South China University of Technology, Guangzhou, China, 2018.

[17] Z. L. Xu, A Brief Course on Elasticity, Higher Education Press, Beijing, China, 1983.

[18] M. Li, Y. B. Zhu, Y. S. Fu et al., "Joint stress analysis of double layer composite lining of shield tunnel for water transport," Journal of China Research Institute of Water Resources and Hydropower Research, vol. 12, no. 1, pp. 109-112, 2014.

[19] M. F. Cai, Rock Mechanics and Engineering, Science Press, Beijing, China, 2013.

[20] D. D. Kong, Y. H. Zhao, P. Wang et al., "Equivalent modulus method for finite element analysis of reinforced concrete materials," Journal of Shenyang Architectural University (Natural Science Edition), vol. 3, pp. 200-203, 2005.

[21] X. He and U. Li, "Analysis of stress disturbance zone of tunnel and its influencing factors," Journal of Railway Science and Engineering, vol. 16, no. 11, pp. 2782-2790, 2019.

[22] S. Y. Chun, H. M. Hai, S. C. Jun et al., "Study on deformation characteristics of composite lining structure of shield tunnel," Advanced Materials Research, vol. 815, pp. 240-245, 2013.

[23] H. J. Gao, P. He, and Z. Chen, "Application of generation layer method in tunnel excavation calculation and analysis," Railway Architecture, vol. 7, pp. 64-67, 2017. 